\title{
Going beyond technocratic and democratic principles: stakeholder acceptance of instruments in Swiss energy policy
}

\begin{abstract}
This paper is about stakeholders' acceptance regarding regulatory instruments in energy policy. We expect that today's introduced instruments not only correspond most to technocratic principles and what elected officials prefer, but that they correlate with the preferences of a wider number of public and private actors in policymaking. We therefore compare the already introduced policy instruments to instrument preferences of the public administration, elected officials, but also NGOs, and utilities. In doing so, we contribute to the question of whether or not the instruments already introduced today correspond to technocratic or democratic principles, or to the preferences of the larger governance arrangement involving other public and private actors. We compare three cantons in Switzerland and gather data through a systematic literature review, expert interviews and surveys. The comparison of the data suggests that the currently selected policy instruments correspond to technocratic principles, but that they also and often correspond to the preferences of public and private actors. More concretely, whereas in one canton NGO preferences align with the introduced instruments, in another canton, this is the case for utilities. In the third canton, all different actor types display similar preferences very much in accordance with the currently employed instrument mix. We thus conclude that depending on the region, different principles and preferences are reflected in the current policy mix.
\end{abstract}

\section{Introduction}

The selection of policy instruments is a core task of political decision-making, and a key element in policy studies. Policy instruments are the "public" tools available to steer and govern, with the aim of changing a target groups' behavior and to reach political goals (Howlett, 2009; Landry \& Varone, 2005). Traditionally, the selection of policy instruments was in the hands of either technocrats/ the public administration, elected officials, or both. Today's research shows that a broad array of actors can be involved in policy instrument selection (Howlett \& Lejano, 2012). Thus, when interested in what ideologies are reflected in today's policies, the study of a variety of stakeholders as well as the values and worldviews they have seems crucial (Weible, 2005). New institutional arrangements emerge, such as collaborative or governance networks, in which policymaking is characterized through selforganization and collective cooperation (Berardo \& Scholz, 2010; Bodin \& Crona, 2009). There is actually an ancient debate as to whether technocratic or democratic principles should dominate policy design (see also Gilley 2017). We try to go beyond this debate and ask if the policy instruments introduced today reflect technocratic or democratic principles, or if they correspond to the preferences of a wider set of actors involved in the larger governance arrangement. (e.g. technocrats/public administration; elected officials, but also NGOs or utilities).

This question is important because if we find evidence that today's instruments do not correspond anymore to the preferences of a large number of politically involved actors, policy may change in the future and current instruments be abolished or suffer correct implementation. And differently, if many stakeholders prefer instruments that are not yet introduced, then new measure might have a real chance to get into the future mix. 
The present paper explores the nexus between criteria of technocratic policy design (e.g., resource intensiveness) (Bressers \& O'Toole, 1998; Dahl \& Lindblom, 1992; Henstra, 2016; Landry \& Varone, 2005; Metz, 2017; Sovacool, 2009; Varone \& Aebischer, 2001), of democracy (i.e., the acceptance of elected officials), and collaborative governance including stakeholder' instrument acceptance (Ansell \& Gash, 2007; Feiock \& Scholz, 2010; Nohrstedt, 2010). In this context, and in line with Peters (2002, 563), we test whether currently introduced policies correspond most to technocratic criteria for policy design, and if they are also legitimized by other stakeholders' acceptance.

Empirically, we study instrument mixes for the promotion of renewable energies in three Swiss cantons (i.e. subnational states). We take a comparative approach because depending on the regional context (e.g. how disputed renewables are, their impact on landscape or the local economy, or best practice examples), there might be important differences in stakeholders' acceptance of policy instruments (typically green NGOs or utilities) and how much they correspond to the acceptance of the administration and elected officials. A comparison of cases furthermore allows a more thorough assessment of potential policy implications.

The Swiss case is ideal because the Fukushima crisis in 2011 constitutes a landmark in Swiss energyrelated policymaking: it marked a radical shift away from nuclear power and towards plans for substantially greater amounts of renewables (RE) (Swiss Federal Department of the Environment, Transport, Energy and Communications DETEC, 2017). To achieve this target, new policy instruments for the promotion of RE are introduced or removed from the policy mix that aims to achieve the energy transition. Other studies about the energy transition mostly cover the impact of policies on the outcome, e.g., the production of renewable electricity or the decrease in carbon emissions (Yi \& Feiock, 2014). Or they investigate why specific renewable energy projects succeed or fail (Martin \& Rice, 2015). We know much less about policy instruments, i.e., the policy output in such transformational settings and about the pathway towards the future policy mix. In this context, going beyond the "technocrats versus democrats" question is particularly interesting: on the one hand, RE strategies are often realized through local projects (e.g., wind farms). The realization of those projects tends to rely heavily upon the acceptance of neighboring communities and the local population, which implies that knowing the preferences of representatives of civil society and the local economy seems key for successful implementation of policy instruments (Wolsink, 2012). On the other hand, if the energy sector is of strategic importance to the state, authorities such as the administration or elected officials might not want to give policy design out of their hands. However, we cannot make inference about what principle (technocratic versus democratic) or stakeholder groups impact today's policy mix or future instrument selection most. However, we can evaluate to what principles and stakeholder preferences today's instruments correspond most. This gives us then the chance to speculate about what instruments might have more or less support in the future.

Methodologically, we implement an innovative combination of approaches. First, we determine the currently implemented policy mix. Second, using three selected technocratic criteria, we evaluate policy instruments that the three Swiss cantons could use for the promotion of RE based on a literature review 
and expert interviews. To obtain a ranking, we employ multi-criteria methods (i.e., ELECTRE TRI) (Roy, 1991, 2016). The use of multi-criteria methods (MCA) in policy design has been repeatedly suggested in recent years in order to provide scholars and decision-makers with more reliable empirical analyses (Howlett, 2004; Schneider, 2012). Third, to assess the stakeholders' acceptance of policy instruments (preferences of technocrats and elected officials, but also, NGOs and utilities) we collected extensive original survey data. The survey comprises of questions aiming to collect information about actors' preferences regarding current and potential future instruments that would enable a renewable energy transition.

\section{Policy mixes and policy design}

The range of measures available to overcome politically-identified problems is vast, and, generally, policy instruments can be used interchangeably ('tool-box' approach) (Landry \& Varone, 2005). However, in recent years, scholars of policy design increasingly acknowledged the complexity of policy selection and shifted their focus from single instruments to multi-tool policy mixes (Gunningham, 2005; Henstra, 2016). Howlett and Rayner (2013), for example, state that policy instruments are rarely introduced on a 'clean slate', i.e., new policy instruments depend on older instruments that were previously implemented. Howlett, Mukherjee, and Rayner (2014) analyze policy design for multifaceted instrument mixes and call for a better evaluation of policy instruments in such intricate situations.

\subsection{Technocratic and democratic principles in policy design}

Policy design evolved during the last decades, and now includes several criteria for instrument evaluation, assessment, or selection (for an overview, see e.g., Metz, 2017). One can distinguish three different generations of instrument analysis based on different criteria:

The first generation of policy scholars strongly emphasized coercion as the main criterion regarding the evaluation of policy instruments (Lowi, 1972). This focus emerged from the ongoing debate between economists and political scientists regarding the interrelation between the state and the market, and how much state intervention versus market freedom was needed. This primarily economic approach centered on the resolution of specific market failures and searched for single policy instruments that were designed to solve one specific problem (Dahl \& Lindblom, 1992). Furthermore, first generation political scientists tended to focus on what the state should have done, rather than what states actually did, thereby missing the empirical aspect of policy (Howlett, 2004, p. 3). The selection and design of policy instruments is, however, not a simple process in which a problem and its solution, as shaped by a policy instrument, have to be identified and implemented by a few decision makers.

Second generation scholars put a more distinct emphasis on the "policy" context, i.e, the broader portfolio of instruments that are already introduced and in what new instruments are embedded in (Bressers \& O'Toole, 1998). The new focus on context illuminated the realization that the introduction or implementation of new policy instruments always depends on the pre-existing policy mix, which 
begs the question of whether 'optimal' policy mixes can ever be developed in the first place (Grabosky, 1994).

A third and most recent generation of scholars further considered the "political" context, i.e politics and the procedural elements in policy design (Howlett \& Rayner, 2007; Metz, 2017). Varone and Aebischer (2001, p. 618) mainly suggest four criteria by which political actors can choose and evaluate policy instruments: (1) Ideological constraints refer to the limitations placed on instrument selection due to existing political ideologies; and most importantly to ideological majorities in parliament. Technocrats will therefore try to opt for instruments that do not encounter ideological constraints and fit ideological majorities in order to effectively pass the political decision-making process (Henstra, 2016). (2) Resource intensiveness, which refers to the intensity of the costs required to operate an instrument administrative personnel, monitoring, enforcement, infrastructure, etc. (3) Targeting precision, which refers to how precisely an instrument is aimed at its targets. Well targeted policy instruments are able to reach the identified target group (Metz, 2017; Schneider \& Ingram, 1993), and induce "real" behavioral change within this target group. (4) Political risk, which is about how visible the instrument and its potential failure are. Decision-makers will avoid the risk of being identified as a supporter of instruments that are unpopular or as the actor that introduced an instrument that failed publicly (Henstra, 2016). The four criteria of Varone and Aebischer (2001) are considered to be universally relevant and very much in line with other typologies, independent from the specific policy field they are applied to (Bressers \& O'Toole, 2005; Henstra, 2016; Howlett, 2015). While the first three criteria are most important to technocrats and concern their tasks in instrument design, implementation and evaluation, the last criterion of political risk is in line with the perspective elected officials adopt then selecting and advocating for instruments.

\subsection{Towards a governance perspective in policy design}

Different scholars (see for example Howlett and Mukherjee (2017); Enzensberger, Wietschel, and Rentz (2002); or Cheng and Yi (2017)) argue that the evaluation of policy instruments strongly depends on the actors that are involved during the policy process. This claim can be seen from a technocratic, a democratic, or a governance perspective:

From a technocratic understanding, policy design is restricted to the public administration. In this view, the administration decisively shapes policies by drafting proposals and re-formulating outlines (eventually with input from the government and parliament) (Sager \& Rosser, 2009).

From a democratic understanding, elected officials represent the citizens and are thus the actor type to focus on when interested in policy design. If policies can be voted upon at the ballot, the mere design of public policies is mostly in the hands of collective actors having the resources (e.g. personnel, money, knowledge, access to information) to actively participate in that game (see Scharpf 1997). One exception are elected officials who have their party and sometimes their staff that helps them translate their ideologies into actual policy proposals. 
Finally, from a governance perspective, policy design is in the hands of a broader network of actors interested in the same goal of addressing a societal problem (Kenis \& Schneider, 1991). These actors represent different levels of decision-making and of implementation processes what contributes to the institutional complexity of modern governance (Hooghe \& Marks, 2002; Lubell, 2013; Lubell \& Edelenbos, 2013). One way to bridge fragmented systems is through collaborative arrangements where public and private stakeholders are brought together to engage in consensus-oriented decision-making (Ansell \& Gash, 2007). In that regard, recent studies emphasize the criterion of stakeholder acceptance, in which the policy preferences of not just elected officials, but also of stakeholders, public, and private actors, are crucial (Dermont, Ingold, Kammermann, \& Stadelmann-Steffen, 2017; Wüstenhagen, Wolsink, \& Bürer, 2007). Research on policy acceptance focuses on the idea that policy instruments are more effectively introduced and later implemented when they are accepted, or even supported, by actors representing different groups, values, and worldviews in a community (Ingold, StadelmannSteffen, \& Kammermann, 2018).

\section{Research design}

In this study we compare different instrument mixes for RE promotion in three Swiss cantons: First, we determine the currently introduced instrument mix in each canton. Second, we determine a policy mix based on the three technocratic criteria of policy selection as outlined in the section just above. Third, we identify the preferred instrument mixes of distinct actor groups (technocrats and elected officials, but also NGOs and utilities) relevant in the domain of RE policy. Before we outline methods used to analyze the data for those two approaches; we introduce the three case-study regions.

\subsection{Selection of case study regions}

The case of energy policy in federalist Switzerland is interesting for several reasons: first, after the Fukushima incident in 2011, the Swiss government decided to phase out the use of nuclear energy. This move arguably boosted the renewable energy market, and required the introduction of new policy instruments to support it. Second, as part of a federalist country, the sub-national entities, the cantons, are the strength behind implementing an energy transition and face significant challenges in reaching targets developed at the national level (Sager, 2017). It is also within the cantons, as well as at the local level, where RE projects will finally be implemented. The success of the projects, however, strongly depends on their acceptance by the private sector and local communities.

The paper specifically analyzes energy policy in the cantons of Bern, Lucerne, and Thurgau. Those cantons display interesting socio-economic and political differences that have an impact on how different public and private actor groups are involved in policy design. Bern is the biggest and most heterogeneous canton in terms of culture (German- and French-speaking parts) as well as in regard to the mix of mountains, lowlands, and urban areas. It is a canton with a long tradition of hydropower. Regarding its size, the strength of the left-wing parties ( $40 \%$ in parliament), and its experience with renewables, we expect to find a true "governance setting" where NGOs and the private sector are well 
organized. This then also means that the policy mix we observe today might be in line with all four actor group preferences (see below for details). Lucerne and Thurgau are more homogenous, smaller cantons, fully German-speaking. In Lucerne, there is some potential for wind energy and also some entrepreneurship promoting this. But all in all, the private sector is less well organized than in Bern and not locally anchored anymore (the main utility being a multi-regional). Thurgau is the wealthiest canton of all three, but also the most conservative with only $15 \%$ of left-wing seats in parliament. Different than in Bern for instance, there are not many landscape protection issues that mobilize green NGOs against renewable installations. So we expect differences in how the different actor groups align in their preferences with the currently introduced policy mix.

Figure 1: Geographic location of cantons

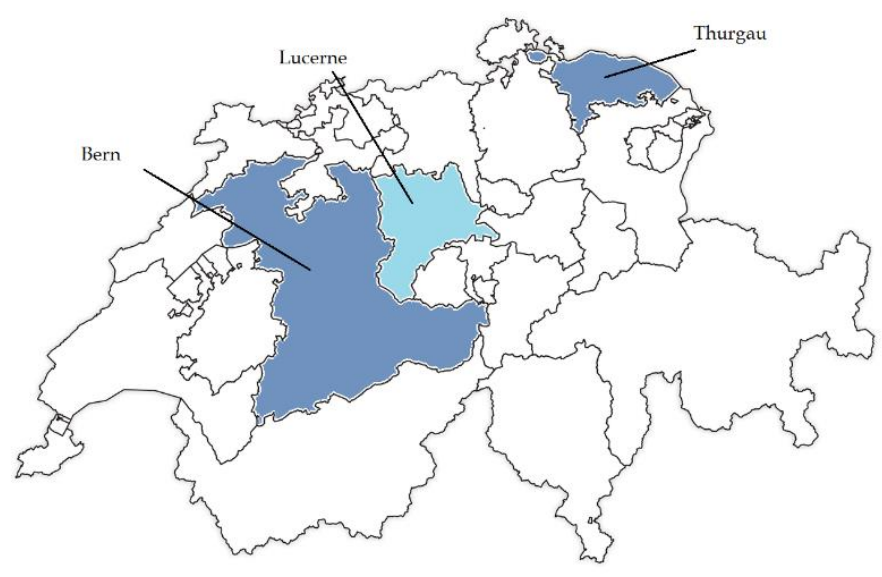

Source: own illustration

3.2. The identification of relevant policy instruments within the RE promotion mix

The breadth of policy instruments available to decision-makers on the cantonal level is vast. In order to produce congruent results, the most relevant instruments for promoting renewable electricity need to be identified. This paper takes a two-fold approach to the pre-selection of instruments: first, we compiled a large list of instruments available to policy makers based on an extensive literature review. Second, we had experts on the Swiss renewable electricity sector (three heads of cantonal energy departments, one representative of the Swiss Federal Office of Energy, as well as one representative each of an NGO and of a utility) evaluate the list in six interviews. During these interviews, the experts were able to select all instruments that they recognized as both technically and legally feasible. Instruments that the experts considered to be fully unrealistic (e.g., a complete ban on non-renewable energies) or not compatible with the Swiss electricity system were removed from the list. The instruments considered for the evaluation are listed in Table 1.

We categorize instruments based on a simple typology that distinguishes between instruments that provide financial incentives and instruments that do not. Instruments that provide financial aid are further separated in such that actively offer subsidies for desired actions and such that allow tax 
reductions. We also distinguish instruments that work with other mechanisms than financial incentives between voluntary and coercive measures (Sovacool, 2009). This typology will allow a more structured and thorough discussion of results later on.

A feed-in tariff is obviously missing in the table; because Switzerland implemented a cost-covering feedin tariff on the national level, none of the experts considered an additional cantonal feed-in tariff to be a realistic policy option due to jurisdictional constraints.

Table 1: Instruments for the promotion of renewable electricity

\begin{tabular}{|c|c|}
\hline Instruments & Description \\
\hline \multicolumn{2}{|l|}{ Non-financial support (voluntary) } \\
\hline Information \& education & $\begin{array}{l}\text { Providing information to the general public and further education courses } \\
\text { to an interested specialized audience by the canton }\end{array}$ \\
\hline Demonstration & $\begin{array}{l}\text { Prototypical function of the canton: e.g., cantons build their own buildings } \\
\text { according to the highest energy standards and thus take a leading role }\end{array}$ \\
\hline \multicolumn{2}{|l|}{ Non-financial support (coercive) } \\
\hline Minimal investment ratio & Implementation of a minimal investment ratio for utilities \\
\hline Partial self-supply (new buildings) & $\begin{array}{l}\text { Newly constructed building are obliged to produce a certain amount of the } \\
\text { used electricity (e.g., based on usable floor area) }\end{array}$ \\
\hline \multicolumn{2}{|l|}{ Financial support (subsidies) } \\
\hline Research & Financial support of energy research for public and private institutions \\
\hline Pilot \& demonstration projects & $\begin{array}{l}\text { Financial support of private or public projects to facilitate market } \\
\text { introduction after successful research }\end{array}$ \\
\hline Subsidy construction & Financial support for construction of renewable electricity projects \\
\hline Subsidy grid access & Financial support for the construction of a grid access \\
\hline Public announcements & Cantonal call for tenders \\
\hline \multicolumn{2}{|l|}{ Financial support (tax reductions) } \\
\hline Reduction of capital cost & $\begin{array}{l}\text { (Partial) cantonal coverage of interests for investment costs; this instrument } \\
\text { would make the construction of new facilities cheaper and less risky }\end{array}$ \\
\hline Tax reduction construction & The costs of construction of renewable electricity can be deducted from taxes \\
\hline Tax reduction on selling RE & $\begin{array}{l}\text { Tax exemption for the sale of renewable electricity up to } 10^{\prime} 000 \mathrm{kWh} / \mathrm{a} \text {; this } \\
\text { instrument would mainly target small private house owners that produce } \\
\text { some of their electricity with (e.g.) PV panels. The limited amount of kWh/a } \\
\text { would not be relevant for larger utilities. }\end{array}$ \\
\hline No tax on selling RE & $\begin{array}{l}\text { Total tax exemption for the sale of renewable electricity; because of the } \\
\text { general exemption this instrument would mainly target large utilities who } \\
\text { produce extensive amounts of (mostly) hydropower. }\end{array}$ \\
\hline $\mathrm{CO}_{2}$ tax compensation & $\begin{array}{l}\text { Compensation of } \mathrm{CO}_{2} \text { tax for companies investing in renewables; this } \\
\text { instrument would mainly target companies from energy intensive industries } \\
\text { and the transportation sector that currently pay large amounts of } \mathrm{CO}_{2} \text { taxes }\end{array}$ \\
\hline
\end{tabular}

\subsection{Operationalizing the technocratic criteria relevant for instrument selection}

Deduced from the literature presented in section 2 above, we can retain three technocratic principles: ideological constraints, resource intensiveness, and targeting precision (Henstra, 2016; Varone \& Aebischer, 2001). We scored the instruments in a two-step procedure: first, we assigned values based on a literature review that takes different instrument characteristics into consideration (see e.g., Henstra, 2016). The evaluation of the policy instruments is based on a literature review of previously conducted assessments of mostly Swiss but also international energy and climate policy. This is why this 
assessment does not consider the specific context (e.g. already introduced policy mix in or financial situation of the jurisdiction) in which the instrument will be introduced, but is a rather general assessment of the performance of each instrument. Ideological constraints are evaluated by judging the chance that their introduction might trigger conflict between the involved actors (Ingold, 2008). For example the introduction of information campaigns will not cause actors to seriously oppose a proposal. However, the potential refund of the $\mathrm{CO}_{2}$-tax goes against some of the core ideologies of the green and left-wing parties and will therefore trigger major opposition during the policy process (Bygrave \& Ellis, 2003). We then evaluate the instruments' resource intensiveness by assessing the administrative and financial costs of implementation, monitoring and operation. Again, an information campaign does not require large administrative engagement or incur major financial costs, whereas fully administering a new subsidy scheme could require both (Metz, 2017; Stavins, 1997). Targeting precision captures the selectivity of an instrument in regards to its impacts on potential target populations. Further education of practitioners, for example, is a highly precise instrument because only people working in the domain of renewable energy are targeted (Henstra, 2016). On the other hand, the obligation to partially selfsupply new buildings targets a much broader group, from private house owners to companies to public organizations (Ingold, 2008; Kellenberger, 2004).

In a second step, we discussed the scores with the same experts that already corroborated the list of instruments. The experts largely agreed with the previously determined scoring of the instruments. In the few occasions experts disagreed with an evaluation we prioritized their assessment over the literature review. We assigned a score of 1 for a 'low', 3 for a 'medium', and 5 for a 'high' performance on each of the three criteria. Scores of 2 and 4 are also possible in the case that an instrument does not directly fit into the low-medium-high scale. We consider a low performance to be 'good' for two criteria: ideological constraints and resource intensiveness. For targeting precision, we consider a high performance to be 'good'. We take this reversed directionality into account when ranking the instruments.

The ranking of the instruments is done based on ELECTRE TRI (Elimination and Choice Expressing Reality) which belongs to the so-called "outranking methods" of multi-criteria analysis (Figueira, Mousseau, \& Roy, 2016; Roy, 1991, 2016). The method has already found some use in renewable energy policy and has been applied in domains such as operations research and energy planning in multiple studies (Beccali, Cellura, \& Mistretta, 2003), or for the evaluation of policy instruments promoting the use of electric vehicles (Taefi, Kreutzfeldt, Held, \& Fink, 2016). A particular advantage of this method is its flexibility regarding the inclusion of multiple qualitative criteria that are crucial for the assessment of the policy instruments presented in this paper.

ELECTRE TRI evaluates different options with a given set of at least three criteria (in this case different instruments are evaluated based on three selection criteria) and orders them according to their performance. The data used for the analysis is set on an ordinal or a weak interval scale. Every score of every instrument is then pair-wise compared to the scores of other instruments for the same criterion so that the different alternatives can be ranked (Figueira et al., 2016). In order to understand the approach 
of ranking options, two main concepts need to be discussed briefly: thresholds and outranking. Generally, policy option A is better than option B when A scores higher on a specific criterion. However, it also matters how much better A is compared to B because minimal differences may not be relevant to political actors (e.g., it does not matter to decision makers whether the implementation of a new subsidy required an expenditure of $\$ 1$ million or $\$ 1.01$ million). ELECTRE TRI therefore uses the so-called indifference threshold that renders small differences in one criterion between two options as insignificant. On the other hand, ELECTRE TRI also employs a preference threshold that qualifies an option as strictly better than another when surpassed. A third threshold particular to ELECTRE TRI is the veto threshold that implies the opposite consideration as the indifference threshold. When an instrument scores significantly higher by one criterion than another instrument, it can be assumed to then veto the worse of the two options. All three thresholds need to be set according to the research interest and may vary across different criteria (Buchanan, Henig, \& Henig, 1998). Based on these three thresholds, ELECTRE TRI compares every instrument with every other instrument (pair-wise comparison) and determines whether one is 'at least as good' or 'not worse' than the second another, i.e., whether it outranks the second instrument regarding one specific criterion. Those scores are then cumulated and transformed into a ranked list of options.

\subsection{Operationalizing policy instrument acceptance}

We evaluate the degree to which each instrument is accepted by different actor types (e.g., administrative entities, elected officials, but also NGOs and utilities). Again in line with the literature presented in section 2, we contrast the above evaluation with the actual preferences of the public administration. And following rules of representative democracy, we are interested in how elected officials assess the policy instruments and to what extent their preferences align with the current mix. And finally, and from a governance perspective, we also assess preferences of NGOs and utilities. We selected those two actor types because both have a special interest in renewables and their regulation. They were furthermore detected as the two most important actor groups following the reputational approach as outlined below. Even though most green NGOs are in favor of alternative energy, there is an increased conflict arising when it comes to landscape protection potentially being hampered or softened through renewable installations. This is not a trivial issue in Switzerland where over $80 \%$ of the landscape is protected. And utilities in contrast are most often the ones who invest in those installations and have an economic interest in the issue. Data to assess the preferences of all those actor types were gathered through standardized surveys. As a first step, we identified the collective actors and organizations involved in RE policy design. Actors were selected according to the positional and decisional approaches for the identification of stakeholders and later confirmed with the reputational approach (see e.g., Magill \& Clark, 1975). In the first wave of contact (September 2016), all actors received a survey questionnaire by postal mail. A second and third attempt to reach actors (late October and December 2016) were then executed by email in which actors had to complete an editable pdf-file. We sent the survey out to all political parties represented in the cantonal parliament (i.e., elected officials); 
to the administrative offices involved in renewable energy policy (i.e., energy, environment, water, special planning and agriculture); as well as to relevant NGOs, utilities, business associations, as well as trade unions and other associations. The paper puts its focus on political parties in parliament for the assessment of elected officials and not on the cantonal governments because all cantonal governments operate under a consensual principle. The consensual character makes government solutions improbable that clearly reflect a specific parties priorities (Vatter, 2016).

Table 2 shows how many actors per actor group were included in the survey. Response rates varied between $78 \%$ in Bern, $68 \%$ in Lucerne, and $65 \%$ in Thurgau. Whereas the response rates may coincidentally differ because of the small sample, we can attribute the varying response rates to different factors. Bern is by far the largest among the three cantons and its political actors are thus more professionalized and more resourceful than the ones in Lucerne and Thurgau.

Table 2: actors initially included in survey by actor group and response rate

\begin{tabular}{lllllllll}
\hline Canton & $\begin{array}{l}\text { Political } \\
\text { parties }\end{array}$ & $\begin{array}{l}\text { Admin. } \\
\text { Entities }\end{array}$ & $\begin{array}{l}\text { Assoc. } \\
\text { (public } \\
\text { entities) }\end{array}$ & $\begin{array}{l}\text { Assoc. } \\
\text { (energy) }\end{array}$ & $\begin{array}{l}\text { Assoc. } \\
\text { (busines } \\
\text { s) }\end{array}$ & Utilities & NGOs & $\begin{array}{l}\text { Response } \\
\text { rate }\end{array}$ \\
\hline Bern & 8 & 4 & 5 & 4 & 9 & 6 & 4 & $78 \%$ \\
Lucerne & 7 & 3 & 3 & 7 & 10 & 3 & 4 & $68 \%$ \\
Thurgau & 9 & 5 & 1 & 6 & 8 & 5 & 3 & $65 \%$ \\
\hline
\end{tabular}

In order to determine the most important actors and actor groups, the survey respondents were asked to indicate which actors they considered the most important in the domain of RE policy making. The respondents were able to make a selection based on the complete list of actors that we include in the survey and had the option to add additional actors they considered relevant. There was no limit on the number of actors that could be selected. This question serves two purposes: first, it functions as a failsafe in case important actors were missed during the initial identification process. Second, the question also determines the most important actors and actor groups within the policy process. The so-called reputation of an actor is considered to be a proxy for their total resources and hence for their influence in the process. For each actor, the amount of times they were mentioned as 'very important' in the process is counted and then divided by the total possible number of possible mentions (i.e., total number of returned survey questionnaires). Actors that receive a value of 1 are considered to be important by everyone, versus a value of 0.5 , which infers that an actor is considered to be important by at least half of all responding actors. We used this question as a proxy for our actor selection; i.e. to select other actor groups besides elected officials and the public administration. We did restrain from including all actor types and only focused on those perceived as important, as some degree of power and resources is needed to decisively impact policy design (Carpenter, 2010; Carpenter \& Krause, 2012). The reputational analysis returned four crucial actor groups: the public administration, the elected officials, environmental NGOs, and utilities. Other actor groups included in the survey received lower reputational levels (i.e., economic associations, trade unions, \& renewable energy businesses) or did not 
return any questionnaires (i.e., science; and administrative entities in Lucerne) and are therefore not considered in the following analysis.

In order to assess the stakeholders' instrument acceptance, survey participants were asked to choose their preferred policy mix to support the expansion of renewable electricity production from the list of instruments presented above. ${ }^{1}$ This question takes into consideration the fact that instruments are hardly ever implemented in an isolated way and makes sure that stakeholders answering the question are able to choose their preferred instruments in a policy mix setting (and not one by one in an isolated manner). In the actual survey, none of the actors chose an 'unrealistic' number of instruments. In other words, all respondents acknowledged that state resources are limited and that not all instruments could be implemented at the same time.

Actors were able to select the primary instruments they would like to employ (assigned value of 1) or, alternatively, in their preferred policy mix (assigned value of 0.5). Instruments they did not choose at all received the value of 0 . We selected the thresholds that indicate whether an instrument should belong to the primary instrument mix based on this coding. This implies that instruments whose score is close to 1 (here $>=0.7$ ) should make part of the primary instrument mix. Instruments that receive a score close to 0 (here $<=0.3$ ) should not be implemented. Instruments with scores in between the two thresholds (thus close to 0.5 ) should be given secondary priority. Furthermore, actors were able to add instruments to the list that they considered were feasible options for achieving the overarching target of increased renewable electricity production. However, this option returned no further relevant insights.

The preferences of the four actor groups are then aggregated. We weight the preferences of administration, elected officials, NGOs, and utilities according to their reputation, and the mean value was utilized as the acceptance indicator. In some cantons, the number of actors involved in renewable energy policy is very low, especially with regard to NGOs and utilities. For these cantons and actor groups, sometimes one single actor had to be taken as a reference.

\section{Analysis}

\subsection{The current instrument mixes}

In a first step, instruments that are currently implemented in the three cantons were identified and are depicted in Table 4. The canton of Lucerne has the most parsimonious instrument mix, which consists solely of two instruments: information \& education, and the canton's prototypical function, i.e. voluntary non-financial support. In the canton of Bern, the current policy mix in the domain of RE promotion consists of information campaigns \& advice from the canton to potential builders, opportunities for further education, financial support for research, pilot, \& demonstration projects, tax reductions for the installation of renewable electricity production, as well as the canton's prototypical

\footnotetext{
${ }^{1}$ The exact wording of the question is as follows (translated from German): “In the following you'll find a selection of potential or already implemented measures that support the expansion of renewable electricity production in the canton of XX. Which of the following measures should, from the position of your organization, be employed primarily or secondarily by the canton of XX? You may add further measures on the blank lines on the bottom of the list."
} 
function in cooperation with the communes (lowest administrative level). This instrument mix thus adds instruments from the financial support through tax reduction category. The canton of Thurgau has the most all-encompassing policy mix regarding the expansion of renewables. Thurgau utilizes the same instruments as the canton of Bern but, in addition, grants subsidies for the construction of projects such as larger PV systems exceeding $30 \mathrm{kWp}$. Further, it is about to implement a partial self-supply standard for building which would force home-owners and businesses to add renewable electricity production installations to their newly constructed buildings. Thurgau thus also adds instruments from the subsidy category.

\subsection{Evaluation of policy mix with technocratic criteria}

Each instrument could attain a score ranging from 1 (low performance) to 5 (high performance) for constraints, resource intensiveness and targeting precision respectively. The distributed scores that were then used for the instruments' pairwise comparison are depicted in Table 3. In order to conduct the MCA-analysis, the thresholds were set as follows: first, the indifference threshold is set at 1 based on the assumption that elected officials and other actors are indifferent or not able to actively distinguish between instruments that have very similar scores in one criterion. Furthermore, all instruments were evaluated qualitatively. An indifference threshold of 1 (compared a threshold of 0 ) prevents the model from assuming outranking relations between instruments that are purely based on coding decisions that might have gone one way or the other. Second, the preference threshold is set at 2, which corresponds to the increment from low to medium or from medium to high. This gap is large enough for actors to clearly distinguish the performance of two instruments without being so large that it would lead to continuous veto relations. Finally, the veto threshold is set at 4 . After running the model, the ranking attained through ELECTRE is then converted to a scale of 0 to 1 . Similarly to the preference scores, scores of 0.7 or higher mean that an instrument should primarily be employed in the policy mix. We transform the final ranking (scale from 0-1) onto the same scale as the instrument preferences actors could express in the survey ( 1 for primary importance of instrument in policy mix; 0.5 for secondary importance; 0 for that instrument should not be part of the policy mix). It is thus easier to compare results. We set the threshold at 0.7 because when splitting the scale of $0-1$ into three sections, 0.7 (rounded up from 0.67 ) is the cut-off for the top tier whereas 0.3 (rounded down from 0.33 ) refers to the bottom tier. Table 4 (column 2) shows the ranking of the selected policy instruments following the MCA method. ${ }^{2}$ The thereby identified technocratic mix is constituted primarily of the following instruments: persuasive measures such as information \& education; the canton's prototypical function; support for research and

\footnotetext{
${ }^{2}$ The MCA model is then evaluated for its robustness. The threshold of indifference is set at 1 . Lowering the threshold to 0 would make the model more sensitive and in this way more vulnerable to small differences in the evaluation of the instruments that might be purely based on the qualitative assessment and coding. An indifference threshold set at 2 would, on the other hand, overstress the assumption that decision makers and other actors are somewhat indifferent about the differences between policy options that have similar attributes. The threshold of preference is set at 2 for all models. Lowering the threshold to 1 is not possible because it would overlap with the indifference threshold. Raising it to 3 is an option as long as the veto threshold is set at 4 or higher. When running, the model with a preference threshold of 3 does not return large differences to the original model. The order of the instruments does not change. The alternate threshold returns, however, a less distinct ranking.
} 
pilot and demonstration projects; and tax reductions granted for the construction of renewable electricity systems.

Table 3: Technocratic criteria scores

\begin{tabular}{|c|c|c|c|}
\hline Instruments & $\begin{array}{l}\text { Ideological } \\
\text { constraints }\end{array}$ & $\begin{array}{c}\text { Resource } \\
\text { intensiveness }\end{array}$ & $\begin{array}{l}\text { Targeting } \\
\text { precision }\end{array}$ \\
\hline \multicolumn{4}{|l|}{ Non-financial support (voluntary) } \\
\hline Information \& education & 1 & 1 & 5 \\
\hline Demonstration (prototypical function of the canton) & 1 & 1 & 5 \\
\hline \multicolumn{4}{|l|}{ Non-financial support (coercive) } \\
\hline Minimal investment ratio & 5 & 5 & 1 \\
\hline Partial self-supply (new buildings) & 4 & 4 & 1 \\
\hline \multicolumn{4}{|l|}{ Financial support (subsidies) } \\
\hline Research & 3 & 3 & 5 \\
\hline Pilot \& demonstration projects & 3 & 3 & 5 \\
\hline Subsidy construction & 4 & 5 & 4 \\
\hline Subsidy grid access & 4 & 5 & 4 \\
\hline Public announcements & 3 & 4 & 4 \\
\hline \multicolumn{4}{|l|}{ Financial support (tax reductions) } \\
\hline Reduction of capital cost & 4 & 3 & 3 \\
\hline Tax reduction construction & 3 & 3 & 5 \\
\hline Tax reduction on selling RE & 3 & 4 & 3 \\
\hline No tax on selling RE & 4 & 5 & 3 \\
\hline $\mathrm{CO}_{2}$ tax compensation & 5 & 4 & 3 \\
\hline \multicolumn{4}{|l|}{ MCA thresholds } \\
\hline Threshold of indifference & 1 & 1 & 1 \\
\hline Threshold of preference & 2 & 2 & 2 \\
\hline Veto threshold & 4 & 4 & 4 \\
\hline
\end{tabular}

Legend: scores refer to: 5 = high; 3 = medium; 1 = low; reading example: the instrument of information \& education has few ideological constraints and a low resource intensiveness. On the other hand its targeting precision is high.

\subsection{The preferred instrument mixes}

Based on the survey results we hereafter present the accepted instrument mixes in the respective canton (Table 4, columns 3-6). In the canton of Bern, the administration prefers an instrument mix that focusses on persuasive measures such as information \& education, pilot projects as well as the canton's prototypical function, tax reductions for the construction of RE projects, and the coercive requirement to partially self-supply new buildings. Elected officials have similar instrument preferences but do not support pilot and demonstration projects. The utilities support an instrument mix that additionally contains financial support for research as well as tax reductions for selling RE, which is of course their core business, and, similarly to all other actor groups, tax reductions for the construction of RE production installations. Environmental NGOs support the most extensive instrument mix, which, in addition to the previously stated instruments, includes financial support for pilot and demonstration projects, as well as a partial tax exemption for selling renewable electricity. All actor groups agree that information \& education as well as demonstration should be employed and that the construction of installations to produce RE should be tax deductible. In the canton of Lucerne, elected officials prefer a similar instrument mix as in Bern. However, they add public announcements to the mix, with a relatively high score of 0.8 , but drop the obligation for partial self-supply. On the other hand, utilities are somewhat restrictive - they want the canton to solely inform and educate the interested public. The 
NGOs again support a rather comprehensive instrument mix that covers financial incentives for research and pilot and demonstration projects as well as the mandate that all newly built buildings produce a certain amount of their required electricity on their own. The canton where actors generally support the most extensive instrument mix is Thurgau: the public administration prefers a very comprehensive mix consisting of multiple persuasive and financial instruments as well as the requirement for the partial self-supply of new buildings. Elected officials are more reluctant to reductions of capital costs and taxes. Utilities, however, are more constrained and focus on the building sector with partial self-supply and on subsidies for the construction of such installations. NGOs mostly agree with this mix and, in addition, support subsidies for the construction of the grid access. ${ }^{3}$

\section{Discussion}

The paper asks if the currently selected instruments in the three cantons correspond to the instruments performing best following three technocratic criteria. We furthermore investigate whether preferences of four actor types, the administration (i.e., technocrats), elected officials, NGOs, and utilities align with the current and observable mix.

In all three cantons, the current mix corresponds to instruments that score highly when considering technocratic principles. In Bern and Thurgau, the mix includes the support of research that has a score of 0.7 what is only slightly above the threshold we consider necessary for high performance from a technocratic perspective. The only considerable exception consists in subsidies for the construction of renewables: this instrument makes part of the mix in Thurgau but receives with 0.1 a very low score following the three technocratic principles. It has a considerable targeting precision but comes with high constraints and is very resource intensive.

One intuitive expectation is that the actor group of the public administration might align the most with the instruments performing best following technocratic principles. It is true that most of the instruments preferred by the administration in Bern and Thurgau also score high in regards of technocratic criteria. But this is not always the case (e.g. in Bern the administration supports partial self-supply and in Thurgau capital cost reductions, both not scoring high from a technocratic perspective) and also other actor groups have the general tendency to prefer instruments with high technocratic performance.

When comparing actors' preferences related to the already introduced mix across the three case studies, interesting insights can be gained: In Bern, the preferences of all three actor groups are very homogenous and align with the introduced mix. This might be the result of the fact that negotiations about renewables have a long tradition in this canton, and that civil society and business are both well organized and integrated in the larger governance arrangement responsible for public policymaking (see e.g., Gerlak, Heikkila, \& Lubell, 2016). Thus actors have the tendency to interact with each other, and to seek policy compromise. In other words, the understanding of the situation, and what is needed in the canton regarding renewables and their regulation, is similar across the different actor groups.

\footnotetext{
${ }^{3}$ Both in Lucerne and Thurgau the number of actors being part of the utility or NGO groups and being active in RE policy is very limited. We thus only have very few responses in the respective groups.
} 
This is much less the case in the other two cantons. In Lucerne, and with the exception of one instrument, NGOs prefer instruments that are not included in the current mix. Whereas in Thurgau, NGOs align much more in their preferences with the current mix than utilities. It is interesting to see that all actor groups find some of their preferred instruments in the current mix. There is no group that aligns systematically with what is introduced.

In what follows, we back-up the results with some more knowledge about the different cases and regional contexts. One interesting insight we gained from our analysis is that experience with an instrument seems to play a crucial role for the alignment of stakeholders' preference and introduced instruments: in the canton of Lucerne, for example, elected officials show major support for public announcements (0.9). Lucerne used to employ this instrument but phased it out due to budgetary restrictions. But in the other two cantons (that do not yet use this instrument), approval is very low (0.2 each). In our case, it can therefore be assumed that decision makers are especially open to instruments they are already familiar with and employ in their canton (Metz \& Ingold, 2017). Generally, it can be further observed that elected officials prefer an instrument mix that consists of slightly less than the currently-implemented instruments. Furthermore, the canton of Lucerne demonstrated the largest discrepancy between what is currently introduced and what elected officials preferred. This can partially be explained by the tense financial situation in the canton, as well as by a failed total revision of the energy act that led to the absence of most instruments.

The NGOs are the actor group that showed the highest preferences for an instrument mix that is more coercive and broader than the mixes favored by the other two actor groups. This finding can mainly be ascribed to their core policy beliefs, which correspond with the idea that NGOs put a much stronger emphasis on issues such as environmental protection and climate change and are generally more favorable towards state intervention than the other two groups (Metz, 2017). This can be directly linked to their stronger support for market-based measures such as tax reductions in exchange for selling renewable electricity or direct subsidies provided by the canton. However, none of the NGOs were in favor of the strongest measure (the complete repeal of taxes on renewable electricity). The hesitation to support this instrument can be attributed to two factors. First, dropping all the taxes on selling renewable electricity would lead to a boom in the planning and construction of power plants (especially dams and wind turbines) in regions that do currently not have any significant infrastructure. NGOs are naturally reluctant to prioritize renewable electricity production over landscape protection. Hence, they also oppose large surges in the construction of power plants, especially in sensitive environmental areas such as near pristine rivers and undeveloped terrain. Second, the electricity industry is a major tax contributor especially on the cantonal but also on the nation level. These taxes are partially used for climate adaptation measures such as flood prevention, or for environmental restoration projects. NGOs therefore also have an interest in not shrinking these taxes.

Whereas the NGOs prefer a more all-encompassing instrument mix, utilities prefer less instruments overall. This finding is also not surprising because most instruments presented in this paper actually support ordinary citizens should they decide to build their own renewable electricity producing system, 
like rooftop solar. This additional power generation is able to help soften the peak electricity consumption times, which occur at noon. However, these new generation systems serve as a form of competition for the utilities, because they start to carve away at the utilities' historical monopoly on electricity production and distribution. Nevertheless, rooftop solar is not yet a fundamental threat to the monopoly maintained by utilities because most private homes that produce renewable electricity are not entirely self-sufficient and are still reliant on the power produced by large-scale power plants. However, this private production of electricity still results in a loss of revenue for the utilities, especially with regard to the current electricity prices and the major investments utilities need in their infrastructure. Furthermore, utilities are obliged by federal law to buy excess electricity and feed it into the grid, which again increases their administrative expenses.

Table 4: The current, technocratic and preferred instrument mixes

\begin{tabular}{|c|c|c|c|c|c|c|}
\hline Bern & $\begin{array}{l}\text { Technocratic } \\
\text { Principles }\end{array}$ & $\operatorname{Admin}(n=2)$ & $\begin{array}{c}\text { Elected officials } \\
\qquad(n=7)\end{array}$ & NGOs $(n=4)$ & Utilities $(n=4)$ & Current mix \\
\hline Instruments & MCA & Pref. & Pref. & Pref. & Pref. & \\
\hline \multicolumn{7}{|l|}{ Non-financial support (voluntary) } \\
\hline Information \& education & 0.8 & 1.0 & 0.8 & 0.9 & 0.8 & $x$ \\
\hline $\begin{array}{l}\text { Demonstration (prototypical } \\
\text { function) }\end{array}$ & 0.9 & 1.0 & 0.8 & 1.0 & 1.0 & $x$ \\
\hline \multicolumn{7}{|l|}{ Non-financial support (coercive) } \\
\hline Minimal investment ratio & 0.0 & 0.0 & 0.3 & 0.5 & 0.1 & \\
\hline Partial self-supply (new buildings) & 0.0 & 1.0 & 0.8 & 0.9 & 0.4 & \\
\hline \multicolumn{7}{|l|}{ Financial support (subsidies) } \\
\hline Research & 0.7 & 0.3 & 0.5 & 0.5 & 1.0 & $x$ \\
\hline Pilot \& demonstration projects & 0.7 & 0.7 & 0.5 & 0.7 & 0.9 & $x$ \\
\hline Subsidy construction & 0.1 & 0.5 & 0.4 & 0.6 & 0.4 & \\
\hline Subsidy grid access & 0.1 & 0.3 & 0.3 & 0.5 & 0.4 & \\
\hline Public announcements & 0.4 & 0.0 & 0.3 & 0.6 & 0.5 & \\
\hline \multicolumn{7}{|l|}{ Financial support (tax reductions) } \\
\hline Reduction of capital cost & 0.4 & 0.2 & 0.5 & 0.7 & 0.3 & \\
\hline Tax reduction construction & 0.7 & 1.0 & 1.0 & 0.8 & 0.9 & $x$ \\
\hline Tax reduction on selling RE & 0.3 & 0.2 & 0.8 & 0.6 & 0.8 & \\
\hline No tax on selling RE & 0.1 & 0.0 & 0.4 & 0.3 & 0.4 & \\
\hline $\mathrm{CO}_{2}$ tax compensation & 0.3 & 0.0 & 0.5 & 0.5 & 0.5 & \\
\hline Lucerne & $\begin{array}{l}\text { Technocratic } \\
\text { Principles }\end{array}$ & $\operatorname{Admin}(n=0)$ & $\begin{array}{l}\text { Elected officials } \\
\qquad(n=6)\end{array}$ & NGOs $(n=3)$ & Utilities $(n=1)$ & Current Mix \\
\hline Instruments & MCA & Pref. & Pref. & Pref. & Pref. & \\
\hline \multicolumn{7}{|l|}{ Non-financial support (voluntary) } \\
\hline Information \& education & 0.8 & NA & 1.0 & 0.3 & 1.0 & $x$ \\
\hline $\begin{array}{l}\text { Demonstration (prototypical } \\
\text { function) }\end{array}$ & 0.9 & NA & 0.9 & 1.0 & 0.5 & $x$ \\
\hline \multicolumn{7}{|l|}{ Non-financial support (coercive) } \\
\hline Minimal investment ratio & 0.0 & NA & 0.5 & 0.6 & 0.0 & \\
\hline Partial self-supply (new buildings) & 0.0 & NA & 0.5 & 1.0 & 0.0 & \\
\hline \multicolumn{7}{|l|}{ Financial support (subsidies) } \\
\hline Research & 0.7 & NA & 0.7 & 0.6 & 0.0 & \\
\hline Pilot \& demonstration projects & 0.7 & NA & 0.6 & 0.9 & 0.5 & \\
\hline Subsidy construction & 0.1 & NA & 0.6 & 1.0 & 0.5 & \\
\hline
\end{tabular}




\begin{tabular}{|c|c|c|c|c|c|c|}
\hline Subsidy grid access & 0.1 & NA & 0.4 & 0.8 & 0.0 & \\
\hline Public announcements & 0.4 & NA & 0.8 & 0.6 & 0.5 & \\
\hline \multicolumn{7}{|l|}{ Financial support (tax reductions) } \\
\hline Reduction of capital cost & 0.4 & NA & 0.5 & 0.6 & 0.5 & \\
\hline Tax reduction construction & 0.7 & NA & 0.9 & 0.6 & 0.5 & \\
\hline Tax reduction on selling RE & 0.3 & NA & 0.6 & 0.4 & 0.0 & \\
\hline No tax on selling RE & 0.1 & NA & 0.3 & 0.0 & 0.0 & \\
\hline $\mathrm{CO}_{2}$ tax compensation & 0.3 & NA & 0.4 & 0.3 & 0.0 & \\
\hline Thurgau & $\begin{array}{l}\text { Technocratic } \\
\text { Principles }\end{array}$ & $\operatorname{Admin}(n=2)$ & $\begin{array}{l}\text { Elected officials } \\
\qquad(n=7)\end{array}$ & NGOs $(n=1)$ & Utilities $(n=1)$ & Current Mix \\
\hline Instruments & MCA & Pref. & Pref. & Pref. & Pref. & \\
\hline \multicolumn{7}{|l|}{ Non-financial support (voluntary) } \\
\hline Information \& education & 0.8 & 0.9 & 0.9 & 1.0 & 0.5 & $x$ \\
\hline $\begin{array}{l}\text { Demonstration (prototypical } \\
\text { function) }\end{array}$ & 0.9 & 1.0 & 0.6 & 1.0 & 1.0 & $x$ \\
\hline \multicolumn{7}{|l|}{ Non-financial support (coercive) } \\
\hline Minimal investment ratio & 0.0 & 0.5 & 0.6 & 0.5 & 0.5 & \\
\hline Partial self-supply (new buildings) & 0.0 & 0.9 & 0.7 & 1.0 & 1.0 & \\
\hline \multicolumn{7}{|l|}{ Financial support (subsidies) } \\
\hline Research & 0.7 & 0.6 & 0.5 & 0.0 & 0.0 & $x$ \\
\hline Pilot \& demonstration projects & 0.7 & 1.0 & 0.9 & 1.0 & 0.5 & $x$ \\
\hline Subsidy construction & 0.1 & 1.0 & 0.8 & 1.0 & 0.5 & $x$ \\
\hline Subsidy grid access & 0.1 & 0.1 & 0.8 & 1.0 & 0.0 & \\
\hline Public announcements & 0.4 & 0.1 & 0.3 & 0.5 & 0.5 & \\
\hline \multicolumn{7}{|l|}{ Financial support (tax reductions) } \\
\hline Reduction of capital cost & 0.4 & 0.9 & 0.1 & 0.5 & 0.5 & \\
\hline Tax reduction construction & 0.7 & 0.1 & 0.6 & 1.0 & 1.0 & $x$ \\
\hline Tax reduction on selling $R E$ & 0.3 & 0.9 & 0.2 & 0.5 & 0.5 & \\
\hline No tax on selling RE & 0.1 & 0.1 & 0.2 & 0.0 & 0.0 & \\
\hline $\mathrm{CO}_{2}$ tax compensation & 0.3 & 0.1 & 0.4 & 0.0 & 0.0 & \\
\hline
\end{tabular}

Legend: highlighted instrument scores show scores $>=0.7$ and indicate instruments primarily relevant for the policy mix. Reading example: In the canton of Bern all actor groups would select the instrument of information and education for their preferred policy mix. Furthermore, also the evaluation by technocratic criteria selects information and education for a potential policy mix.

\section{Conclusion}

This paper assesses whether previously selected instrument mixes correspond to technocratic criteria in policy design or to preferences of central stakeholders in the policy process. To answer this question, we compare the introduced policy mix to policy mixes derived from technocratic principles and survey data. In doing so, we try assess whether the currently introduced policy instruments correspond mostly to technocratic or democratic principles, or if they align most with the preferences of public and private actors integrated in the larger governance arrangement. We argue that this question is highly relevant, especially in the fields of energy policy and transition. Within these fields, the acceptance of new options not only depends upon the state's strategies, but also on the perceived legitimacy of the instruments, the broader political context, and preferences of a wide array of concerned actors (Ingold et al., 2018). If the preferences of central actors do not mirror the currently implemented policy mix, they might 
challenge it in the future. By doing so, unsatisfied actors might destabilize current regulation and push to either introduce new instruments or remove old ones from the mix (Kivimaa \& Kern, 2016).

We empirically investigate policy instruments introduced in Swiss energy policy and focus on three sub-national entities, called cantons. We identify technocratic policy mixes by conducting a multicriteria analysis (ELECTRE TRI) and assess actors' preferences as acquired through an elite survey in the cantons of Bern, Lucerne, and Thurgau. Generally, the instruments introduced score highly when it comes to their technocratic performance. But the picture is more complex than that. The general conclusion we can draw is that regional contexts matter. In the canton of Bern with the longest experience of renewable energy promotion, the different actor types including NGOs and utilities have all coherent and comparable preferences in how to regulate renewable energies in the canton. And those preferences largely align with the introduced mix. This is different in the two smaller cantons, with less experience and more conservative parliaments. In Lucerne, for instance, preferences of NGOs and utilities are almost not reflected at all in the current mix. These actors might thus push for the introduction of their preferred instruments such as extensive subsidies in the case of NGOs. In Thurgau, preferences of all actor types only partially match what is introduced. Here, we could speculate that the coercive instrument of mandatory partial self-supply in new buildings might be introduced because all actor groups (public administration, elected officials, NGOs and utilities) accept the instrument already. A fact that might hinder its introduction, is the instrument's low scores regarding technocratic principles.

Our result is thus very much in line with current research about the performance of so-called collaborative governance arrangements. Collaborative governance follows the assumption - and some existing empirical evidence - that the participation of affected, concerned, and responsible actors enhances the acceptance of decisions; which consequently supports implementation, and therefore improves the quality of outcomes (Macnaghten \& Jacobs, 1997). Mainly in environmental policy studies, scholars show some evidence that deliberative, bottom-up ways of problem solving can improve outcomes (Berkes, Colding, \& Folke, 2002; Christensen, Kornov, \& Nielsen Holm, 2012; Newig, 2012). Our research is not going thus far, but shows some tendency that more homogenous preferences among different actor types can exist in settings with a longer, collaborative tradition in policy design. And such "negotiated agreements" (as it might be possible, for example, in the case of Thurgau with its selfsupply regulation) might then also have an impact on the quality in implementation, and finally the policy outcome.

The study has its inherent limitations. The elephant in the room is the missing direct causal link between the currently introduced policy mix and the constructed technocratic and preferred instrument mixes. The paper does not assume that its analysis can be used to find direct causal connections between the three mixes. However, what the paper is able to do is compare the three cantons and offer insights about what policy instruments have a high potential of being introduced in the future or removed from the policy mix (if already introduced but with low acceptance scores by key stakeholders). 
Another important limitation of the study is that there are other factors which enable or restrict choices around policy instruments that have not been discussed in detail. These factors include, for example, path dependency and therefore the instruments that are already in place, budgetary limitations, etc. (see e.g., Öberg, Lundin, \& Thelander, 2015). This paper is also an attempt to integrate MCA into policy design on a theoretical level. There are many sophisticated decision tools and therefore more criteria, that impact decision-making than this study analyzes (see e.g., Henggeler Autunes \& Oliveira Henriques, 2016). However, the more theoretical design criteria have rarely been applied in the way that this paper does.

In sum, this paper shows that policy design criteria as well as actors' preferences are a valuable element of analyzing policy design and understanding current policy mixes. It seems most relevant for the adoption of future policy mixes which aim to foster the deployment of renewable electricity to focus on instruments that score well with all three, technocratic, democratic and governance principles. This is especially true for decision makers, as they are the primary actor group in charge of instrument selection and need to be aware of the factors that are often crucial for other actor groups. Elected officials need to consider the acceptance of other stakeholder or actor groups when making a final choice. This paper gives insights to elected officials, as well as to other actors, into how they might structure and justify their instrument selection in highly complex policy mix situations.

\section{Funding \& Acknowledgments}

\section{$[\ldots]$}

\section{References}

Ansell, C., \& Gash, A. (2007). Collaborative Governance in Theory and Practice. Policy Studies Journal, 18, 543-571. https://doi.org/10.1093/jopart/mum032

Beccali, M., Cellura, M., \& Mistretta, M. (2003). Decision-making in energy planning. Application of the Electre method at regional level for the diffusion of renewable energy technology. Renewable Energy, 28, 2063-2087. https://doi.org/10.1016/S0960-1481(03)00102-2

Berardo, R., \& Scholz, J. T. (2010). Self-Organizing Policy Networks: Risk, Partner Selection, and Cooperation in Estuaries. American Journal of Political Science, 54, 632-649. https://doi.org/10.1111/j.1540-5907.2010.00451.x

Berkes, F., Colding, J., \& Folke, C. (2002). Navigating Social-Ecological Systems. Cambridge: Cambridge University Press.

Bodin, Ö., \& Crona, B. I. (2009). The role of social networks in natural resource governance: What relational patterns make a difference? Global Environmental Change, 19, 366-374. https://doi.org/10.1016/j.gloenvcha.2009.05.002

Bressers, H. T. A., \& O'Toole, L. J. (1998). The Selection of Policy Instruments: A Network-Based Perspective. Journal of Public Policy, 18(3), 213-239.

Bressers, H. T. A., \& O'Toole, L. J. (2005). Instrument Selection and Implementation in a Networked Context. In F. P. Eliadis, M. M. Hill, \& M. Howlett (Eds.), Designing government: From instruments to governance (pp. 132-153). Montreal: McGill-Queen's Univ. Press.

Buchanan, J. T., Henig, E. J., \& Henig, M. I. (1998). Objectivity and subjectivity in thedecision making process. Annals of Operations Research, 80, 333-346. https://doi.org/10.1023/A:1018980318183 
Bygrave, S., \& Ellis, J. (2003). Policies to Reduce Greenhouse Gas Emissions in Industry: Successful Approaches and Lessons Learned: Workshop Report. Paris.

Carpenter, D. P. (2010). Reputation and power: Organizational image and pharmaceutical regulation at the FDA. Princeton studies in American politics. Princeton: Princeton University Press. Retrieved from http://www.jstor.org/stable/10.2307/j.ctt7t5st

Carpenter, D. P., \& Krause, G. A. (2012). Reputation and Public Administration. Public Administration Review, 72, 26-32. https://doi.org/10.1111/j.1540-6210.2011.02506.x

Christensen, P., Kornov, L., \& Nielsen Holm, E. (2012). Between governance and government: Danish EIA in uncharted waters. Journal of Environmental Assessment Policy and Management, 14, 1-18. https://doi.org/10.1142/S1464333212500214

Dahl, R. A., \& Lindblom, C. E. (1992). Politics, economics, and welfare. New Brunswick: Transaction Publ.

Dermont, C., Ingold, K., Kammermann, L., \& Stadelmann-Steffen, I. (2017). Bringing the policy making perspective in: A political science approach to social acceptance. Energy Policy, 108, 359-368. https://doi.org/10.1016/j.enpol.2017.05.062

Feiock, R. C., \& Scholz, J. T. (2010). Self-organizing federalism: Collaborative mechanisms to mitigate institutional collective action dilemmas. Cambridge: Cambridge University Press.

Figueira, J. R., Mousseau, V., \& Roy, B. (2016). ELECTRE Methods. In S. Greco, M. Ehrgott, \& J. R. Figueira (Eds.), Multiple criteria decision analysis: State of the art surveys (pp. 155-186). New York, Heidelberg, Dordrecht, London: Springer.

Gerlak, A. K., Heikkila, T., \& Lubell, M. (2016). The Promise and Performance of Collaborative Governance. In S. Kamieniecki \& M. E. Kraft (Eds.), The Oxford handbook of U.S. environmental policy. Oxford: Oxford University Press. https://doi.org/10.1093/oxfordhb/9780199744671.013.0019

Grabosky, P. N. (1994). Green Markets: Environmental Regulation by the Private Sector. Law \& Policy, 16, 419-448. https://doi.org/10.1111/j.1467-9930.1994.tb00132.x

Gunningham, N. (2005). Reconfiguring Environmental Regulation. In F. P. Eliadis, M. M. Hill, \& M. Howlett (Eds.), Designing government: From instruments to governance (pp. 333-352). Montreal: McGillQueen's Univ. Press.

Henggeler Autunes, C., \& Oliveira Henriques, C. (2016). Multi-Objective Optimization and MultiCriteria Analysis Models and Methods for Problems in the Energy Sector. In S. Greco, M. Ehrgott, \& J. R. Figueira (Eds.), Multiple criteria decision analysis: State of the art surveys (pp. 1071-1170). New York, Heidelberg, Dordrecht, London: Springer.

Henstra, D. (2016). The tools of climate adaptation policy: Analysing instruments and instrument selection. Climate Policy, 16, 496-521. https://doi.org/10.1080/14693062.2015.1015946

Hooghe, L., \& Marks, G. N. (2002). Types of Multi-Level Governance. SSRN Electronic Journal. Advance online publication. https:// doi.org/10.2139/ssrn.302786

Howlett, M. (2004). Beyond Good and Evil in Policy Implementation: Instrument Mixes, Implementation Styles, and Second Generation Theories of Policy Instrument Choice. Policy and Society, 23, 1-17. https://doi.org/10.1016/S1449-4035(04)70030-2

Howlett, M. (2009). Governance modes, policy regimes and operational plans: A multi-level nested model of policy instrument choice and policy design. Policy Sciences, 42, 73-89. https:// doi.org/10.1007/s11077-009-9079-1

Howlett, M. (2015). Policy analytical capacity: The supply and demand for policy analysis in government. Policy and Society, 34, 173-182. https://doi.org/10.1016/j.polsoc.2015.09.002

Howlett, M., \& Lejano, R. P. (2012). Tales From the Crypt. Administration \& Society, 45, 357-381. https://doi.org/10.1177/0095399712459725 
Howlett, M., Mukherjee, I., \& Rayner, J. (2014). The Elements of Effective Program Design: A Two-Level Analysis. Politics and Governance, 2, 1. https:/ / doi.org/10.17645/pag.v2i2.23

Howlett, M., \& Rayner, J. (2007). Design Principles for Policy Mixes: Cohesion and Coherence in 'New Governance Arrangements'. Policy and Society, 26, 1-18. https://doi.org/10.1016/S14494035(07)70118-2

Howlett, M., \& Rayner, J. (2013). Patching vs Packaging in Policy Formulation: Assessing Policy Portfolio Design. Politics and Governance, 1, 170-182. https://doi.org/10.12924/pag2013.01020170

Ingold, K. (2008). Analyse des mécanismes de décision: le cas de la politique climatique suisse. Politikanalyse: Vol. 8. Zürich: Rüegger.

Ingold, K., Stadelmann-Steffen, I., \& Kammermann, L. (2018). The Acceptance of Instruments in Policy Mix Situations: A Citizens' Perspective on the Swiss Energy Transition. Conference Paper.

Kellenberger, S. (2004). Les instruments volontaires dans la politique climatique et énergétique Suisse: motifs de leur motifs de leur introduction et chances de leur application. Chavannes-Lausanne. Retrieved from IDHEAP website: https://serval.unil.ch/resource/serval:BIB_72204C123592.P001/REF

Kenis, P., \& Schneider, V. (1991). Policy Networks and Policy Analysis: Scrutinizing a New Analytical Toolbox. In B. Marin \& R. Mayntz (Eds.), Policy Networks: Empirical evidence and theoretical considerations (pp. 25-59). Frankfurt am Main, Boulder, Colorado: Campus-Verl.; Westview Pr.

Kivimaa, P., \& Kern, F. (2016). Creative destruction or mere niche support?: Innovation policy mixes for sustainability transitions. Research Policy, 45, 205-217. https://doi.org/10.1016/j.respol.2015.09.008

Landry, R., \& Varone, F. (2005). Choice of policy instruments: confronting the deductive and the interactive approaches. In F. P. Eliadis, M. M. Hill, \& M. Howlett (Eds.), Designing government: From instruments to governance (pp. 106-131). Montreal: McGill-Queen's Univ. Press.

Lowi, T. J. (1972). Four Systems of Policy, Politics, and Choice. Public Administration Review, 32, 298. https://doi.org/10.2307/974990

Lubell, M. (2013). Governing Institutional Complexity: The Ecology of Games Framework. Policy Studies Journal, 41, 537-559. https:// doi.org/10.1111/psj.12028

Lubell, M., \& Edelenbos, J. (2013). Integrated Water Resources Management: A Comparative Laboratory for Water Governance. International Journal of Water Governance, 1, 177-196. https:// doi.org/10.7564/13-IJWG14

Macnaghten, P., \& Jacobs, M. (1997). Public identification with sustainable development: investigating cultural barriers to participation. Global Environmental Change, 7(1), 5-24.

Magill, R. S., \& Clark, T. N. (1975). Community Power and Decision Making: Recent Research and Its Policy Implications. Social Service Review, 49(1), 33-45.

Martin, N., \& Rice, J. (2015). Improving Australia's renewable energy project policy and planning: A multiple stakeholder analysis. Energy Policy, 84, 128-141. https://doi.org/10.1016/j.enpol.2015.04.034

Metz, F. (2017). Explaining policy design with network structures. A comparison of water protection policies for the reduction of micropollutants in four Rhine river riparian countries. Berlin, Heidelberg: Springer.

Metz, F., \& Ingold, K. (2017). Politics of the precautionary principle: assessing actors' preferences in water protection policy. Policy Sciences, 50, 721-743. https://doi.org/10.1007/s11077-017-9295-z

Newig, J. (2012). More Effective Natural Resource Management through Participatory Governance? Taking Stock of the Conceptual and Empirical Literature - and Moving Forward. In K. Hogl, E. Kvarda, R. Nordbeck, \& M. Pregernig (Eds.), Environmental Governance. Edward Elgar Publishing. https://doi.org/10.4337/9781849806077.00011 
Nohrstedt, D. (2010). Do Advocacy Coalitions Matter?: Crisis and Change in Swedish Nuclear Energy Policy. Journal of Public Administration Research and Theory, 20, 309-333. https://doi.org/10.1093/jopart/mun038

Öberg, P., Lundin, M., \& Thelander, J. (2015). Political Power and Policy Design: Why Are Policy Alternatives Constrained? Policy Studies Journal, 43, 93-114. https://doi.org/10.1111/psj.12086

Roy, B. (1991). The outranking approach and the foundations of electre methods. Theory and Decision, 31, 49-73. https://doi.org/10.1007/BF00134132

Roy, B. (2016). Paradigms and Challenges. In S. Greco, M. Ehrgott, \& J. R. Figueira (Eds.), Multiple criteria decision analysis: State of the art surveys (pp. 19-42). New York, Heidelberg, Dordrecht, London: Springer.

Sager, F. (2017). Infrastrukturpolitik: Verkehr, Energie und Telekommunikation. In P. Knoepfel, I. Papadopoulos, P. Sciarini, A. Vatter, \& S. Häusermann (Eds.), NZZ Libro. Handbuch der Schweizer Politik: Manuel de la politique Suisse (6th ed., pp. 721-748). Zürich: Verl. Neue Zürcher Zeitung.

Schneider, A. (2012). Policy design and transfer. In E. Araral, S. Fritzen, M. Howlett, M. Ramesh, \& X. Wu (Eds.), Routledge Handbook of Public Policy. Routledge. https://doi.org/10.4324/9780203097571.ch17

Schneider, A., \& Ingram, H. (1993). Social Construction of Target Populations: Implications for Politics and Policy. The American Political Science Review, 87, 334-347. https://doi.org/10.2307/2939044

Sovacool, B. K. (2009). The importance of comprehensiveness in renewable electricity and energyefficiency policy. Energy Policy, 37, 1529-1541. https:// doi.org/10.1016/j.enpol.2008.12.016

Stavins, R. N. (1997). Environmental Protection: The Changing Nature of National Governance. Retrieved from Harvard University - Harvard Kennedy School (HKS) website: https://ssrn.com/abstract=11016

Swiss Federal Department of the Environment, Transport, Energy and Communications DETEC. (2017). Energy Strategy 2050. Retrieved from https://www.uvek.admin.ch/uvek/en/home/ energy/energy-strategy-2050.html

Taefi, T. T., Kreutzfeldt, J., Held, T., \& Fink, A. (2016). Supporting the adoption of electric vehicles in urban road freight transport - A multi-criteria analysis of policy measures in Germany. Transportation Research Part a: Policy and Practice, 91, 61-79. https://doi.org/10.1016/j.tra.2016.06.003

Varone, F., \& Aebischer, B. (2001). Energy efficiency: The challenges of policy design. Energy Policy, 29, 615-629. https:// doi.org/10.1016/S0301-4215(00)00156-7

Vatter, A. (2016). Das politische System der Schweiz (2nd ed.). Baden-Baden: Nomos.

Weible, C. M. (2005). Beliefs and Perceived Influence in a Natural Resource Conflict: An Advocacy Coalition Approach to Policy Networks. Political Research Quarterly, 58, 461-475. https://doi.org/10.1177/106591290505800308

Wolsink, M. (2012). The research agenda on social acceptance of distributed generation in smart grids: Renewable as common pool resources. Renewable and Sustainable Energy Reviews, 16, 822-835. https://doi.org/10.1016/j.rser.2011.09.006

Wüstenhagen, R., Wolsink, M., \& Bürer, M. J. (2007). Social acceptance of renewable energy innovation: An introduction to the concept. Energy Policy, 35, 2683-2691. https:// doi.org/10.1016/j.enpol.2006.12.001

Yi, H., \& Feiock, R. C. (2014). Renewable Energy Politics: Policy Typologies, Policy Tools, and State Deployment of Renewables. Policy Studies Journal, 42, 391-415. https://doi.org/10.1111/psj.12066 